\title{
Der Wirtschafts-, Sozial- und Umweltrat
}

Im Jahre 1958 in seiner "modernen " Formen zum ersten Mal in eine französische Verfassung aufgenommen, kann dieser Rat auf eine bis 1925 zurückreichende Tradition zurückblicken. Insgesamt gehören diesem weitgehend einflusslosen Gremium 233 Mitglieder an, die zu etwa drei Vierteln von den verschiedenen gesellschaftlichen Gruppen entsandt und zu einem knappen Viertel von der Regierung auf fünf Jahre ernannt werden.

Entscheidungsbefugnisse besitzen weder die monatlich wenigstens einmal tagende Versammlung noch die sieben Sektionen für besondere Themenbereiche. Vielmehr dient der Rat ausschließlich den anderen Staatsorganen als Beratungsgremium. Er widmet sich vornehmlich folgenden Aufgaben: Förderung der $\mathrm{Zu}$ sammenarbeit der verschiedenen Berufsgruppen, Mitwirkung an der Wirtschaftsund Sozialpolitik der Regierung, Stellungsnahmen zu wirtschaftlichen, sozialen, umweltpolitischen und technologischen Maßnahmen und Projekten - in all diesen Bereichen in Ausübung einer eigenständigen Initiativbefugnis; weiterhin gutachterliche Äußerungen zu Gesetzesvorlagen nach Aufforderung des Premierministers. Zusätzlich verlangt Artikel 70 der Verfassung obligatorische Stellungnahmen bei den wirtschaftlichen Rahmenplänen und bedeutenden Sozial- sowie Umweltmaßnahmen. 